ISSN: 2707-756X

DOI: $10.32996 /$ jeltal

Journal Hompage: www.al-kindipublisher.com/index.php/jeltal

\title{
Grammatical Structures in the Written and Oral Mode of ESL Students
}

Rischelle G. Aggabao

Faculty, College of Education, Isabela State University, Cabagan, Isabela, Philippines

Corresponding Author: Rischelle G. Aggabao, E-mail: rischelle.g.aggabao@isu.edu.ph

\section{ARTICLE INFORMATION ABSTRACT}

Received: November 08, 2020

Accepted: December 14, 2020

Volume: 2

Issue: 5

DOI: 10.32996/jeltal.2020.2.5.6

\section{KEYWORDS}

Phrase structure rules, grammatical structures, nominals, adjectivals, adverbials
This study focuses on the survey of frequency and occurrence of phrase structure rules used in the written and oral mode of first year tertiary ESL students. It describes the sentence-embedded structures namely, nominal, adjectival and adverbial. As far as phrase structure rules are concerned, the constituents of the noun phrase, verb phrase, adjectival phrase and adverbial phrase are given structural labels. The researcher made use of the quantitative description of the oral and written structures of 76 first year students enrolled in a language class. The results of the study show that majority of the students write their essay using nominals followed by adverbials and the least used are adjectivals. In the oral mode, the most commonly used phrase structure rules are adverbials, followed by nominals and the least used are adjectivals. Though students have a good command of English in writing and speaking, they should be exposed to different communicative situations and develop a balanced style in expressing meaning using varied grammatical structures.

\section{Introduction}

The systematic study of how learners acquire competency of the English language is a recent phenomenon of this century. Communication becomes accessible to people in a global village through international networking where interaction between people has expanded way beyond their local communities. A well-known fact is, people have had to learn the second language as a means of obtaining an education or securing an employment, as such, there is an obvious need to discover more about how second language is learned.

One approach the learners engage in a learning process is to use the second language in speech or writing. The focus of language includes formal features of language that linguists have concentrated on. One example might be the pronunciation; how learners' accents change over time. Another might be the words learners use; how learners build up their vocabulary. Learners study a specific grammatical structure such as plurals, noun-verb concord, relative clauses; grammatical sentence patterns such as subject-verb-object; and how learners are able to produce these structures.

The grammaticality of a language relies on its structures, (though a sentence, whether grammatical or not has a certain structure) and the meaning produced from these structures. The form of language interacts with meaning applying the correct usage of grammar in both writing and speaking based on prescriptive rules of the English language.

When learners study the rules of language, it becomes his basis in constructing sentences according to those rules. This is observed especially in writing than in speaking. Learners build their own language within the linguistic parameters or social context.

How students acquire a second language and how they use it is one approach that would provide valuable insights to the researcher. What students actually do reflect on the actual learning process when they engage in speech or writing and analyze them carefully. These samples serve as evidence on their knowledge about the second language. In learning the

K C AL-KINDI CENTER $\mathbf{R}$ D FOR RESEARCH Your gatewoy to world-class research
Published by Al-KindiCenter for Research and Development. Copyright (c) the author(s). This is an open access article under CC BY license (https://creativecommons.org/licenses/by/4.0/) 
target language, learners become fluent when they are exposed to an environment when they are able to hear and speak the language. The input they receive and what type of input that occurs facilitates learning. It is inherent to the learners that they possess general knowledge about the language and this mechanism helps them extract information about the second language as their input.

Learners have already their native language and we can expect them to draw on this and learn the second language. Learners are equipped with cognitive mechanisms that would help them understand a new language and make effective use of their knowledge in communicating- both in written and speech. For example, learners internalize bits of language structure before they acquire the rules. Linguistic features are analyzed so that they can construct grammatical structures. The systematic learning of structures (morphemes and syntax) requires that they learn a written or spoken expression in a way that they are learning some kind of a rule and how it is expressed in the light of a context.

The use of language arbitrarily depends on what kind of meaning they convey. Meaning is modified to suit the speaker's intention. Upon using the second language, speakers follow the standard rules on grammar and logical sequence. English, as medium in communication, considers grammar to achieve clarity in expressing the message. Grammar becomes the essence of giving significant meaning through logical arrangement of words. Words uttered contain embeddings or phrases depending on its length and concreteness. From the samples, the researcher can identify what particular sentence pattern is commonly used for both written and oral modes.

The researcher deemed it necessary to identify grammatical sentence structures that would help learners determine which sentence structure conveys grammatical patterns and contrast which grammatical patterns are conventionally used in writing.

\section{Methodology}

\subsection{Research Design}

The researcher makes a quantitative description of the oral and written structures of First year students. In this study, the phrase structure rules together with the structures resulting from sentence embedding such as nominal, adjectival, adverbial were examined.

The researcher assigned a topic entitled, "How to care for the environment" for the written activity. For the speech presentation, "How can I improve the socio-economic plight of the country." The strategy used in generating ideas is freewriting for the written text and extemporaneous mode of speech is employed. The speech delivered was later transcribed so that the researcher can look carefully what phrase structures are evident.

\subsection{Data Analysis}

The researcher considered only the grammatical sentences and were subjected to linguistic analysis. Misspelled words were regarded in determining the grammaticality of the sentence when they did not affect the meaning conveyed. Compound words joined by a hyphen were considered as one word. Names and expressions that normally go together were counted as one. Contractions were considered as two words.

\subsection{Statistical Tool Used}

The researcher determined the implication of phrase structure rules to the written and oral mode in terms of frequency of occurrence of the most commonly used phrase structure rules.

\section{Discussion of Results}

The researcher presents the data from the samples on written and oral category relevant to the understanding of this study.

Table 1: Frequency of occurrence and ranking of PS rules for " $S$ "

\begin{tabular}{lcccccc}
\hline Subject & \multicolumn{3}{c}{ Written Mode } & \multicolumn{3}{c}{ Oral Mode } \\
\hline & Frequency & Percentage & Rank & Frequency & Percentage & Rank \\
$\mathrm{S} \longrightarrow(\mathrm{sm}) \mathrm{S}$ & 14 & 100 & 1 & 66 & 100 & 1 \\
Subj Pred & 0 & & & 0 & &
\end{tabular}




\begin{tabular}{llccc}
\hline & comp 'S & 0 & 0 & \\
& comp (sm) S & 0 & & 0 \\
Total & 14 & 100 & 66 & 100 \\
\hline
\end{tabular}

Table 1 reflects the results on the frequency and ranking of PS Rules for the Sentence. It shows that students use sentence modifiers with a frequency of 14 in writing the sentences and 66 in their speech presentation.

Table 2: Frequency and occurrence of ranking of PS rules for sentence modifier

\begin{tabular}{|c|c|c|c|c|c|c|}
\hline & \multicolumn{3}{|c|}{ Written Mode } & \multicolumn{3}{|c|}{ Oral Mode } \\
\hline & Frequency & Percentage & Rank & Frequency & Percentage & Rank \\
\hline $\mathrm{sm} \longrightarrow \mathrm{Advl}$ & 14 & 23.33 & 2 & 66 & 70.21 & 1 \\
\hline neg/not & 46 & 76.67 & 1 & 28 & 29.79 & 2 \\
\hline Total & 60 & 100 & & 94 & 100 & \\
\hline
\end{tabular}

Table 2 shows that few have mentioned adverbials as sentence modifiers and in some cases students mention negations in asserting positive implications. Sentence modifiers are expressed in adverbial, which is most frequently used by the students in the written and oral mode.

Table 3: Frequency of occurrence and ranking of PS rules for noun phrase as predicate nominal

\begin{tabular}{lcccccc}
\hline \multicolumn{1}{c}{ NP } & \multicolumn{3}{c}{ Written Mode } & \multicolumn{3}{c}{ Oral Mode } \\
\hline & Frequency & Percentage & Rank & Frequency & Percentage & Rank \\
NP & 263 & 12.6 & 3 & 123 & 6.5 & 5 \\
NP det N & 412 & 19.8 & 2 & 257 & 13.5 & 2 \\
NP det AP N & 135 & 6.5 & 6 & 119 & 6.2 & 6 \\
NP AP N & 146 & 7 & 5 & 130 & 6.8 & 4 \\
NP det N Prep N & 105 & 5 & 7 & 183 & 9.6 & 3 \\
S & 12 & .6 & 8 & 34 & 1.8 & 9 \\
NP S & 9 & .4 & 9 & 64 & 3.4 & 8 \\
NP1 NP2 & 176 & 8.5 & 4 & 72 & 3.8 & 7 \\
NP Pro & 823 & 39.6 & 1 & 920 & 48.4 & 1 \\
Total & 2081 & $100 \%$ & & 1902 & $100 \%$ & \\
\hline
\end{tabular}

Table 3 shows the frequency of occurrence and ranking of PS Rules for NP as predicate nominal. The NP expressed as Pronoun is most frequently used by the Accountancy students. The noun phrase as NP followed by a determiner is frequently used while NP as noun is quite often used in writing. What is sometimes used is NP as NP1 NP2 while a noun followed by an adjective phrase is rarely used in writing their compositions. 
From the table, NP as Pronoun is determined as most frequently used in making their speech followed by NP as det N which is frequently used. NP- det N followed by Prep N is quite often used. The AP N as predicate nominal is sometimes used. NP as simple noun is rarely used. The use of Pronoun as predicate nominal suggests that students prefer a nominative to express ideas without repeating the same word in the entire speech.

Table 4: Frequency of occurrence and ranking of PS rules for noun phrase as subject, object, object of the preposition and predicate nominal

\begin{tabular}{lcccccc}
\hline Noun Phrase & \multicolumn{3}{c}{ Written Mode } & \multicolumn{3}{c}{ Oral Mode } \\
\hline & Frequency & Percentage & Rank & Frequency & Percentage & Rank \\
Subject & 1133 & 61.4 & 1 & 1387 & 76.08 & 1 \\
Object & 246 & 13.3 & 3 & 170 & 9.32 & 3 \\
$\begin{array}{l}\text { Object of the } \\
\text { Preposition }\end{array}$ & 369 & 20 & 2 & 215 & 11.8 & 2 \\
Predicate Nominal & 98 & 5.3 & 4 & 51 & 2.8 & 4 \\
Total & 1846 & $100 \%$ & & 1823 & $100 \%$ & \\
\hline
\end{tabular}

Table 4 presents the frequency of occurrence and ranking of PS Rules for Noun Phrase as Subject, Object, Object of the Preposition and Predicate Nominal. The students have mostly used frequently NP's as Subject in the written and oral mode. The least used NP is predicate nominal.

Table 5: Frequency of occurrence and ranking of PS rules for predicate

\begin{tabular}{|c|c|c|c|c|c|c|c|}
\hline \multicolumn{2}{|c|}{ Predicate } & \multicolumn{3}{|c|}{ Written Mode } & \multicolumn{3}{|c|}{ Oral Mode } \\
\hline & & Frequency & Percentage & Rank & Frequency & Percentage & Rank \\
\hline \multirow[t]{2}{*}{ Pred } & $\rightarrow$ An VP & 294 & 37.5 & 2 & 256 & 26.5 & 2 \\
\hline & Aux VP (Advl) & 489 & 62.5 & 1 & 709 & 73.5 & 1 \\
\hline Total & & 783 & $100 \%$ & & 965 & $100 \%$ & \\
\hline
\end{tabular}

This table reveals the frequency of occurrence and ranking of PS Rules for Predicate formed as verb. The Predicate expressed as auxiliary verb phrase (function is adverbial) has ranked higher than for the predicate expressed as auxiliary verb phrase. The result suggests that auxiliary VP is more frequently used than VP as adverbial in a predicate of a sentence.

Table 6: Frequency of occurrence and ranking of PS rules for auxiliary

\begin{tabular}{cccccccc}
\hline Verb & \multicolumn{3}{c}{ Written Mode } & \multicolumn{3}{c}{ Oral Mode } \\
\hline & & Frequency & Percentage & Rank & Frequency & Percentage & Rank \\
Verb $\rightarrow$ Aux T & 693 & 43.58 & 1 & 708 & 34.57 & 1 \\
M & 392 & 24.65 & 2 & 531 & 25.92 & 2 & \\
to (inf) & 208 & 13.08 & 3 & 257 & 12.54 & 3 \\
-ing & 73 & 4.6 & 6 & 199 & 9.72 & 5
\end{tabular}




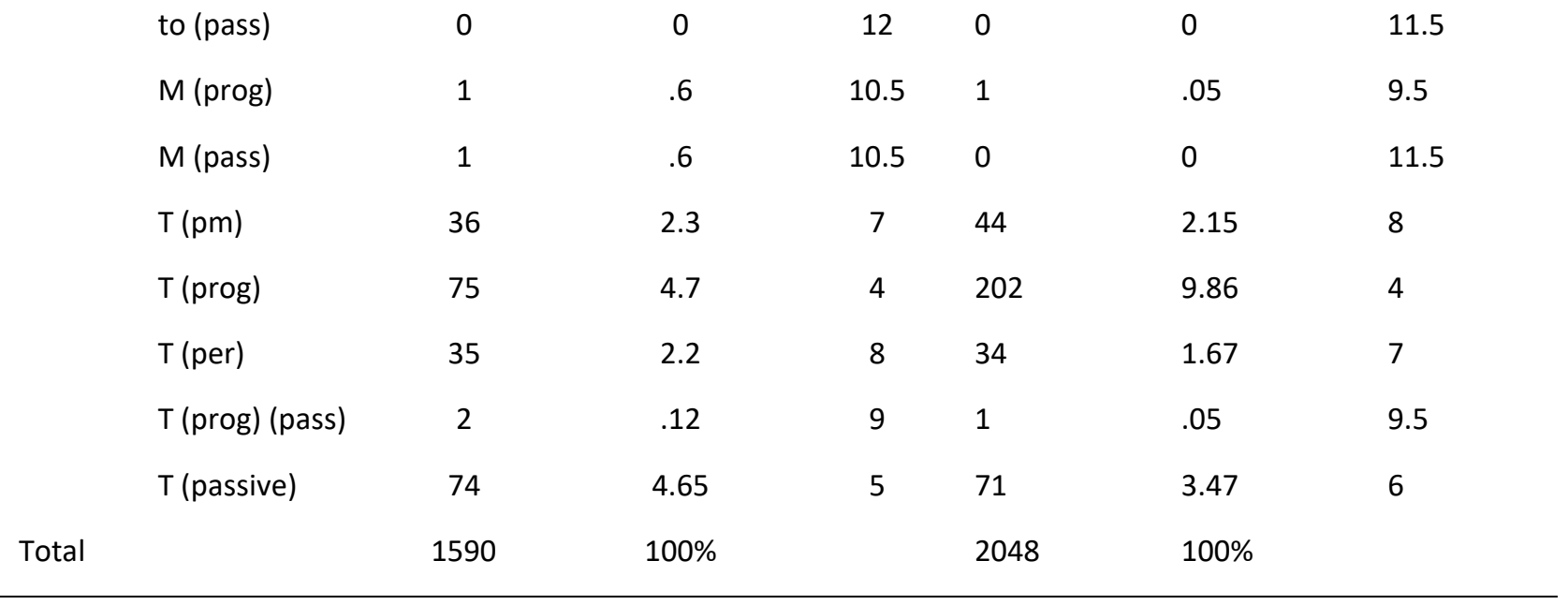

Verbs show action, mood and tense. Verbs expressed as auxiliary transitive is most frequently used. The modal auxiliary verb is frequently used. Verbs in the form of infinitive are quite often used. Verbs in the progressive form are sometimes used and rarely are verbs in the passive tense.

In the oral mode, the auxiliary verb followed by a transitive is the most commonly used verb in the oral mode. Modal verbs ranked second as frequently used and quite often used is the infinitive verb. Progressive tense is sometimes used unlike -ing participle which is rarely used in student's speech. The auxiliary is expressed as transitive verbs and these verbs carry actions that give mental images to listeners.

Table 7: Frequency of occurrence and ranking for tense

\begin{tabular}{lcccccc}
\hline Tense & \multicolumn{3}{c}{ Written Mode } & \multicolumn{3}{c}{ Oral Mode } \\
\hline & Frequency & Percentage & Rank & Frequency & Percentage & Rank \\
Present & 809 & 82.05 & 1 & 890 & 78.41 & 1 \\
Past & 109 & 11.05 & 2 & 87 & 7.67 & 3 \\
Future & 68 & 6.9 & 3 & 158 & 13.92 & 2 \\
Total & 986 & $100 \%$ & & 1135 & $100 \%$ & \\
\hline
\end{tabular}

Table 7 describes how frequently verbs in different tenses are used in expressing the action done. Seemingly, Present tense is most frequently used followed by past tense, that is, frequently used. What the students-respondents sometimes use is the future tense. The data imply that students prefer writing the action done in the present tense to elicit immediate response with the reader.

Moreover, student- respondents expressed action most frequently in the present tense. Next is future tense and past tense. In speaking, the listeners would focus on the immediate and future action rather than the past. This is one factor why students prefer making their speeches using present tense or future tense frequently.

Table 8: Frequency and occurrence and ranking of PS rules for verb phrase

\begin{tabular}{lcccccc}
\hline Verb Phrase & \multicolumn{3}{c}{ Written Mode } & \multicolumn{3}{c}{ Oral Mode } \\
\hline & Frequency & Percentage & Rank & Frequency & Percentage & Rank \\
VP $\rightarrow$ cop NP & 173 & 12.30 & 3 & 318 & 17.84 & 2 \\
cop AP & 85 & 6.05 & 6 & 153 & 8.58 & 6
\end{tabular}




\begin{tabular}{lcccccc} 
cop Prep P & 15 & 1.07 & 10.5 & 30 & 1.68 & 9 \\
V NP & 386 & 27.45 & 1 & 387 & 21.7 & 1 \\
V NP Prep P & 236 & 16.79 & 2 & 279 & 15.65 & 3 \\
NP1 NP2 & 76 & 5.4 & 7 & 99 & 5.56 & 7 \\
PV & 6 & .43 & 12.5 & 3 & .17 & 14 \\
PV NP & 15 & 1.07 & 10.5 & 12 & .67 & 10.5 \\
PV NP Prep P & 6 & .43 & 12.5 & 4 & .22 & 12.5 \\
PV Prep P & 39 & 2.77 & 8 & 12 & .67 & 10.5 \\
V Prep P & 168 & 11.95 & 4 & 269 & 15.09 & 4 \\
V NP S & 2 & .14 & 14 & 4 & .22 & 12.5 \\
V S & 38 & 2.70 & 9 & 49 & 2.75 & 8 \\
V & 161 & 11.45 & 5 & 164 & 9.2 & 5 \\
\hline
\end{tabular}

Table 8 shows the frequency of occurrence and ranking of verb phrase expressed in different forms. The verb phrase expressed as Verb followed by NP is most frequently used in writing statements. A verb followed by NP and Pre P is frequently used. A subject followed by a copula and NP is quite often used in writing simple sentences. A verb followed by Prep $\mathrm{P}$ is sometimes used and rarely used is a simple verb.

The most frequently used verb is expressed as V followed by NP in the oral mode. The VP expressed as copula followed by NP is frequently used while VP as V followed by NP as Prep P is quite often used. Rarely students use phrasal verb in writing and speaking.

Table 9: Frequency of occurrence and ranking of PS rules for adjectival phrase

\begin{tabular}{|c|c|c|c|c|c|c|c|}
\hline \multicolumn{2}{|c|}{ Adjectival Phrase } & \multicolumn{3}{|c|}{ Written Mode } & \multicolumn{3}{|c|}{ Oral Mode } \\
\hline & & Frequency & Percentage & Rank & Frequency & Percentage & Rank \\
\hline & $\longrightarrow$ Adj & 438 & 89.39 & 1 & 763 & 95.14 & 1 \\
\hline & intens Adj & 47 & 9.59 & 2 & 39 & 4.86 & 2 \\
\hline & intens Adj & 1 & .20 & 4 & 0 & & 3.5 \\
\hline & Prep P & & & & & & \\
\hline & Adj $S$ & 4 & .82 & 3 & 0 & & 3.5 \\
\hline & Total & 490 & $100 \%$ & & 802 & $100 \%$ & \\
\hline
\end{tabular}

Based on the table, simple adjectives are mostly used words that modify NPs. Using adjectives with intensifier is frequently used by the students. The implication is students are more exposed to simple adjectives than using complex form of modifiers. The adjective followed by a Subject is quite often used and sometimes used are adjectives with intensifier followed by a prepositional phrase found in students' essay. 
Adjectival phrase expressed as adjective is most frequently used followed by adjectives with intensifier. Quite often used in speech are adjective as intensifier followed by a prepositional phrase and adjective followed by a subject. Simple adjective is mostly used because it is easier to grasp during speech.

Table 10: Frequency and occurrence of PS rules for adverbial in sentence initial, medial, final position

\begin{tabular}{lcccccc}
\hline Adverbial & \multicolumn{3}{c}{ Written Mode } & & \multicolumn{2}{c}{ Oral Mode } \\
\hline & Frequency & Percentage & Rank & Frequency & Percentage & Rank \\
Advl Cl & 185 & 47.68 & 1 & 537 & 62.66 & 1 \\
Advl P & 56 & 14.43 & 3 & 89 & 10.39 & 3 \\
Prep P & 147 & 37.89 & 2 & 231 & 26.95 & 2 \\
Total & 388 & $100 \%$ & & 857 & $100 \%$ & \\
\hline
\end{tabular}

This table presents the frequency of occurrence of adverbs in a sentence. The most frequently used adverb is an adverbial clause (conj $+S+V$ ) followed by Prep P and Advl P. Students have more familiarity in using common notions on adverbs rather using other words that function as an adverb.

Table 10 also reveals the results on frequency of adverbs in the oral mode. Students mostly use adverbs frequently as clauses, next is, prepositional phrase and adverbial phrase. It implies that adverbs are popularly expressed in clauses in modifying phrases in the sentence.

Table 11: Frequency of occurrence and ranking of prepositional phrase in noun phrase, verb phrase, adjective phrase and adverbial

\begin{tabular}{|l|c|c|c|c|c|c|}
\hline Prepositional Phrase & \multicolumn{3}{|c|}{ Written Mode } & \multicolumn{3}{c|}{ Oral Mode } \\
\hline & Frequency & Percentage & Rank & Frequency & Percentage & Rank \\
\hline Prep P in NP & 121 & 62.05 & 1 & 20 & 8.73 & 2 \\
\hline Prep in VP & 2 & 1.03 & 4 & 0 & 0 & .07 \\
\hline Prep P in AP & 5 & 2.56 & 3 & 2 & 90.4 & 3 \\
\hline Prep P in Advl & 67 & 34.36 & 2 & 207 & $100 \%$ & 1 \\
\hline Total & 195 & $100 \%$ & & 857 & & \\
\hline
\end{tabular}

Table 11 shows the frequency of occurrence and ranking of prepositional phrase used in a NP, VP, AP and Adverbial. Prepositional phrase used in noun phrase, the most frequently used because of its standard form- a preposition and a noun first that signify one phrasal unit. The adverb indicated in a Prep $P$ is frequently used. Adjective phrase that consist a preposition is quite often used while prepositions in a verb phrase is sometimes used. This means that students have insufficient knowledge on its function.

The table presents the prepositional phrase in NP, VP, AP and Adverb expressed in prepositional phrases has the highest response, or most frequently used followed by Prep $\mathrm{P}$ in a noun phrase as frequently used. Quite often used is Prep $\mathrm{P}$ in adjectival phrase unlike for Prep $P$ in a verb phrase with a zero frequency. 
Table 12: Frequency of occurrence of sentence-embedded nominals, adjectivals and adverbials

\begin{tabular}{lcccccc}
\hline Categories & \multicolumn{3}{c}{ Written Mode } & Oral Mode \\
\hline & Frequency & Percentage & Rank & Frequency & Percentage & Rank \\
Nominals & 228 & 75 & 1 & 47 & 5.31 & 2 \\
Adjectivals & 62 & 20.39 & 2 & 39 & 4.41 & 3 \\
Adverbials & 14 & 4.61 & 3 & 799 & 90.28 & 1 \\
Total & 304 & $100 \%$ & & 885 & $100 \%$ & \\
\hline
\end{tabular}

Table 12 shows the frequency of occurrence and ranking of sentence-embedded nominals (most frequently used), adjectivals (frequently used) and adverbials (quite often used). Table 35 presents the frequency of occurrence of sentence-embedded nominals, adjectivals and adverbials. Among the categories in the oral mode, adverbials are the most frequently used followed by nominals and adjectivals which is interpreted as frequently used and quite often used respectively.

Table 13: Frequency and occurrence of sentence-embedded nominals

\begin{tabular}{lcccccc}
\hline Nominal & \multicolumn{3}{c}{ Written Mode } & \multicolumn{3}{c}{ Oral Mode } \\
\hline & Frequency & Percentage & Rank & Frequency & Percentage & Rank \\
Noun Compound & 44 & 53.66 & 1 & 4 & 8.33 & 2 \\
Appositive & 33 & 40.24 & 2 & 43 & 89.58 & 1 \\
Objective & 5 & 6.1 & 3 & 1 & .5 & 3 \\
Complement & 82 & $100 \%$ & & 48 & $100 \%$ & \\
Total & & & & &
\end{tabular}

Table 13 reveals the frequency and occurrence of sentence-embedded nominals. Nominals expressed in a noun compound are most frequently used. NPs as nominal in the appositive case are frequently used. The objective complement is quite often used. This may be the effect of what sentence pattern is easier to use and require students less facility for the target language.

As for nominals in the oral mode, table 13 shows the most frequently used- the appositive case followed by noun compound and objective complement. The appositive gives a short description on the function of the NP as Subject.

Table 14: Frequency of occurrence and ranking of noun phrase complements as sentence- embedded nominals

\begin{tabular}{lcccccc}
\hline NP Complement & \multicolumn{3}{c}{ Written Mode } & \multicolumn{3}{c}{ Oral Mode } \\
\hline & Frequency & Frequency & Percentage & Frequency & Frequency & Percentage \\
that cl & 82 & 40 & 1 & 54 & 35.06 & 2 \\
for..to cl & 6 & 2.93 & 5 & 8 & 5.19 & 4.5 \\
inf cl & 49 & 23.9 & 2.5 & 8 & 5.19 & 4.5 \\
-ing cl & 19 & 9.27 & 4 & 26 & 16.88 & 3
\end{tabular}




\begin{tabular}{|c|c|c|c|c|c|}
\hline wh- cl & 49 & 23.9 & 2.5 & 58 & 37.66 \\
\hline Total & 205 & & & 154 & $100 \%$ \\
\hline
\end{tabular}

Table 14 shows the frequency of occurrence and ranking of noun phrase complements as sentence-embedded nominals. Most respondents have used frequently the that clause. The infinitive clause and wh-clause is interpreted as frequently used and the -ing clause is quite often used. Sometimes used is the for..to.. clause.

In the oral mode, wh- clause has been the most frequently used with a frequency of 58 followed by that clause or frequently used and quite often used is the -ing clause. The infinitive clause and for.. to.. clause are sometimes used. It is observed that speeches that begin with a question attract the audience to listen attentively and find out the resolution for the query.

Table 15: Frequency of occurrence and percentage of sentence-embedded adjectivals

\begin{tabular}{lcccccc}
\hline Adjectivals & \multicolumn{3}{c}{ Written Mode } & & Oral Mode \\
\hline & Frequency & Percentage & Rank & Frequency & Percentage & Rank \\
Attributive & 587 & 100 & 1 & 1451 & 97.71 & 2 \\
Predicate & 0 & & 2 & 34 & 29 & 100 \\
Total & 587 & 100 & & 1485 & \\
\hline
\end{tabular}

It can be deduced from this table that the most frequently used type of adjective is attributive than adjectives used as predicates. This table reveals that students use most frequently of attributive adjectives in the oral mode followed by adjectives in the predicate mode in both categories.

Table 16: Frequency of occurrence and percentage of sentence-embedded attributive adjectivals

\begin{tabular}{|c|c|c|c|c|c|c|}
\hline \multirow[t]{2}{*}{ Adjectivals } & \multicolumn{3}{|c|}{ Written Mode } & \multicolumn{3}{|c|}{ Oral Mode } \\
\hline & Frequency & Percentage & Rank & Frequency & Percentage & Rank \\
\hline Simple Adjectivals & 492 & 78.47 & 1 & 988 & 76.59 & 1 \\
\hline $\begin{array}{l}\text { Adjective } \\
\text { Compound }\end{array}$ & 67 & 10.69 & 2 & 224 & 17.36 & 2 \\
\hline Participial Adjective & 59 & 9.41 & 3 & 61 & 4.73 & 3 \\
\hline Genetive 's & 8 & 1.28 & 4 & 17 & 1.32 & 4 \\
\hline Adverb & 1 & .16 & 5 & 0 & & \\
\hline Coordinates & 0 & & & 0 & & \\
\hline Total & 627 & 100 & & 1290 & 100 & \\
\hline
\end{tabular}

Further elaboration of attributive adjectivals present in the data reveals that simple adjectives are most frequently used, adjective compounds are frequently used, participial adjective is quite often used, the genetive 's is sometimes used and adverb as adjective is rarely used. The coordinate adjective has never been used by the students-respondents in written and oral modes. 
Table 17: Frequency of occurrence and percentage of sentence-embedded predicative adjectivals

\begin{tabular}{lcccccc}
\hline $\begin{array}{l}\text { Predicative } \\
\text { Adjectivals }\end{array}$ & \multicolumn{7}{c}{ Written Mode } & & Oral Mode \\
& Frequency & Percentage & Rank & Frequency & Percentage & Rank \\
Word Modifiers & 0 & & 3 & 0 & 0 & 3 \\
Phrase Modifiers & 161 & 70 & 1 & 182 & 70 & 1 \\
Clause Modifiers & 69 & 30 & 2 & 75 & 30 & 2 \\
Total & 230 & 100 & & 260 & 100 & \\
\hline
\end{tabular}

Sentence -embedded predicative adjectivals occur in the form of phrase modifiers, which are most frequently used; clause modifiers, which are frequently used; and word modifiers, which students are probably not familiar with its use and may depend on the topic- related structure.

Sentence -embedded predicative adjectivals occur in the form of phrase modifiers, which are most frequently used; clause modifiers, which are frequently used; and word modifiers, which students are probably not familiar with its use and may depend on the topic- related structure.

Only three students have mentioned word modifiers unlike in the written mode with zero frequency. This implies that students have limited knowledge on this type.

Table 18: Frequency of occurrence of sentence embedded initial, medial and final adverbials

\begin{tabular}{lcccccc}
\hline Phrases & \multicolumn{3}{c}{ Written Mode } & \multicolumn{3}{c}{ Oral Mode } \\
\hline & Frequency & Percentage & Rank & Frequency & Percentage & Rank \\
Participial & 17 & 6.75 & 3 & 1 & .34 & 3 \\
Prep P & 179 & 71.03 & 1 & 212 & 71.38 & 1 \\
Adv P & 56 & 22.22 & 2 & 84 & 28.28 & 2 \\
Total & 252 & $100 \%$ & & 297 & $100 \%$ & \\
\hline
\end{tabular}

Table 18 projects the frequency of occurrence of adverbs in their initial, medial, final position. Prepositional phrase as adverbial is most frequently used followed by adverbial phrase and participial phrase. The table implies that in a sentential structure, the prepositional phrase as adverbial is widely used in modifying verbs or adjectives. Prepositional adverb is the most frequently used followed by adverbial phrase and participial phrase with only one frequency.

Table 19: Frequency of occurrence and ranking of sentence-embedded medial adverbials

\begin{tabular}{lcccccc}
\hline Medial Adverbial & \multicolumn{5}{c}{ Written Mode } & Oral Mode \\
\hline & Frequency & Percentage & Rank & Frequency & Percentage & Rank \\
Frequency & 24 & 18.46 & 3 & 17 & 9.4 & 5.5 \\
Manner & 56 & 43.08 & 1 & 70 & 38.67 & 1 \\
Probability & 6 & 4.62 & 5 & 1 & .55 & 7 \\
Intensifier & 3 & 2.31 & 6 & 17 & 9.4 & 5.5
\end{tabular}




\begin{tabular}{lcccccc} 
Limit & 10 & 7.69 & 4 & 20 & 11.05 & 4 \\
Usuality & 2 & 1.54 & 7 & 26 & 14.36 & 3 \\
Time & 29 & 22.3 & 2 & 30 & 16.57 & 2 \\
Total & 130 & $100 \%$ & & 181 & $100 \%$ & \\
\hline
\end{tabular}

Table 19 presents the frequency of occurrence of sentence embedded adverbials in their medial position. The adverb of manner is frequently used in telling the degree of the action performed. The adverb of time is frequently used unlike adverb of frequency which is quite often used. The adverb of limit is sometimes used and stating the probability is rarely used. Students are more familiar with the function of adverb of manner among other kinds of adverbs.

The table shows that adverb of manner is most frequently used by the respondents followed by adverb of time determined as frequently used. The adverb of usuality is quite often used and rarely for Adverb of frequency and intensifier.

Table 20: Frequency of occurrence and ranking of sentence-embedded final adverbials

\begin{tabular}{|c|c|c|c|c|c|c|}
\hline Final Adverbial & & ritten Mode & & Oral Mode & & \\
\hline & Frequency & Percentage & Rank & Frequency & Percentage & Rank \\
\hline Prep P & 25 & 8.71 & 3 & 18 & 4 & 3 \\
\hline Adv P & 33 & 11.5 & 2 & 30 & 6.7 & 2 \\
\hline Clauses & 229 & 79.79 & 1 & 400 & 89.2 & 1 \\
\hline Total & 287 & $100 \%$ & & 448 & $100 \%$ & \\
\hline
\end{tabular}

Table 20 shows the frequency of adverbials in their final position in sentence- embedded form. Final adverbs expressed in clauses are most frequently used rather than adverbial phrases and prepositional phrases.

As perceived from the table, clauses are mostly used. This is evident both in the oral and written mode. Clauses lengthen a sample sentence and this variation is being carried out in writing an essay or preparing a speech material.

If we look closely at the table, adverbial phrases are frequently used followed by prepositional phrase, which is quite often used.

Table 21: Frequency of occurrence and ranking of prepositional phrases as final adverbials

\begin{tabular}{|c|c|c|c|c|c|c|}
\hline \multirow[t]{2}{*}{ Prep $P$ in Final Adverb } & \multicolumn{3}{|c|}{ Written Mode } & \multicolumn{3}{|c|}{ Oral Mode } \\
\hline & Frequency & Percentage & Rank & Frequency & Percentage & Rank \\
\hline Locative & 12 & 26.67 & 1 & 6 & 22.22 & 1 \\
\hline Manner & 7 & 15.56 & 4 & 4 & 14.81 & 2.5 \\
\hline Time & 10 & 22.22 & 2.5 & 4 & 14.81 & 2.5 \\
\hline Frequency & 0 & 0 & 7.5 & 2 & 7.41 & 5.5 \\
\hline Purpose & 4 & 8.89 & 5 & 2 & 7.41 & 5.5 \\
\hline Reason & 10 & 22.22 & 2.5 & 1 & 3.7 & 7 \\
\hline
\end{tabular}




$\begin{array}{lcccccc}\text { Duration } & 2 & 4.4 & 6 & 8 & 9.63 & 4 \\ \text { Accomplishment } & 0 & 0 & 7.5 & 0 & 0 & 8 \\ \text { Total } & 45 & 100 \% & & 27 & 100 \%\end{array}$

Table 21 shows the prepositional phrases as final adverbials. Prepositional adverb expressed as locative is the most frequently used. Prepositional phrase expressed as time and reason is frequently used while Adverb of manner is sometimes used and rarely used is Adverb of purpose.

Among adverbs in the final position expressed as prepositional phrase, adverb of location is the most frequently used followed by adverb of manner and time. Adverb of duration is sometimes used while adverb of frequency and purpose is rarely used in the oral mode.

Table 22: Frequency of occurrence and ranking of clauses in sentence-embedded initial adverbials

\begin{tabular}{lcccccc}
\hline Clauses & \multicolumn{5}{c}{ Written Mode } & \multicolumn{2}{c}{ Oral Mode } \\
\hline & Frequency & Percentage & Rank & Frequency & Percentage & 2 \\
If clause & 40 & 12.5 & 2 & 84 & 15.70 & 1 \\
Sub clause & 280 & 87.5 & 1 & 451 & 84.30 & $100 \%$ \\
Total & 320 & $100 \%$ & & 535 &
\end{tabular}

Table 22 shows the frequency of clauses in sentence-embedded adverbial in initial position. Subordinating clause in sentenceembedded adverbial is more frequently used than if clause. Perhaps the topic does not require much of conditional clauses or the students are more inclined in writing imperative sentences complex in form. Subordinating clause is most frequently used followed by a conditional clause in both modes.

Table 23: Frequency of occurrence and ranking of clauses in sentence-embedded final adverbials

\begin{tabular}{|c|c|c|c|c|c|c|}
\hline \multirow[t]{2}{*}{ Final Adverb } & \multicolumn{3}{|c|}{ Written Mode } & \multicolumn{3}{|c|}{ Oral Mode } \\
\hline & Frequency & Percentage & Rank & Frequency & Percentage & Rank \\
\hline If clause & 17 & 6.4 & 3 & 19 & 4.69 & 3 \\
\hline Infinitive clause & 41 & 15.5 & 2 & 130 & 32.1 & 2 \\
\hline -ing participle & 1 & .38 & 4 & 15 & 3.7 & 4 \\
\hline -ed participle & 0 & 0 & 5 & 2 & .49 & 5 \\
\hline Subordinating clause & 206 & 77.7 & 1 & 239 & 59.01 & 1 \\
\hline Total & 265 & $100 \%$ & & 405 & $100 \%$ & \\
\hline
\end{tabular}

Table 23 shows the occurrence of clauses in sentence-embedded adverbial in final position. Subordinating clause received the highest frequency interpreted as most frequently used. The infinitive clause as frequently used and quite often used is if clause. The -ing participle is sometimes used and rarely or none for -ed participle. This clearly shows that students are apt in adapting a pattern using adverbial conjunctions expressed in clauses. Table 46 describes clauses as final adverbs. The most frequently used is a subordinating clause. The infinitive clause is frequently used while if clause is quite often used. Next is, ing participle is sometimes used unlike -ed participle which is rarely used. Both in the oral and written mode, students mostly use subordinating clauses. 


\section{Conclusions and Recommendations}

Based on the written outputs of the students, the researcher found out that the most commonly used among phrase structures is a noun phrase expressed as pronouns. Students mostly state their ideas using nominals and pronominal to recall personal encounters. In beginning their essay, the subject is in NPs and the most commonly used pattern is S-V-O. This pattern consists of two nouns- the subject and the object of the verb. Second most used are adverbials. This pattern comes in prepositions that function as adverbs. Students focused more in embedding prepositional phrases to make sentences appear longer thus neglecting modifiers in developing a vivid context. Adjectivals are the least used in the sentence structure. The students opt more to modify phrases with adverbial phrases rather than adjectives.

On the other hand, adverbials are the most commonly used in speaking. Students prefer emphasizing the subject using adverbial modifiers. Seldom students use adjectives as modifiers. Nominals commonly occur in the written mode but less used in speech. This may be attributed to a situation where students prefer conveying ideas through its condition and manner.

Adjectives, or words that modify a noun or pronoun least to appear in the oral mode. Students are more exposed in giving details as concrete and abstract rather than descriptive.

To attain a good command of foreign language learners should be exposed to it in genuine circumstances and with natural frequency or painstakingly study lexis and syntax assuming that student have some contact with natural input. It is advisable to provide learners with contexts which would exemplify how native users of language take advantage of anaphoric references, ellipses, articles, and other grammar related elements of language which, if not crucial are at least particularly useful for proficient communication. The students must practice writing sentences with varied patterns to express meaning. For teachers, adapt samples that would widen learners' capability to express their ideas in various sentence patterns. Teachers can provide a checklist of grammatical structures for students to practice composing sentences in small groups. Teachers and students' interaction, i.e., peer tutoring and mentoring may reinforce knowledge and skills of grammatical structures. Studies may also be conducted to examine grammatical structures of the learner's first language and second language and how these linguistic features be integrated in teaching communication.

\section{References}

[1] Celce-Murcia, M. \& Larsen-Freeman, D. (2008). The Grammar Book. Heinle.

[2] Gitlin, G. (2010). The cognition of grammatical structures. Procedia Social and Behavioral Sciences, 2(2), 4147-4151. https://doi: 10.1016/j.sbspro.2010.03.655

[3] Khoshsima, H. and Tanhaei, R. (2014). The impact of teaching grammatical structures on writing ability of Iranian students. International Journal of Applied Linguistics \& English Literature, 3(6), 134-138. https://doi:10.7575/aiac.ijalel.v.3n.6p.134

[4] Nunan, D. (1999). Second language teaching and learning. Heinle \& Heinle Publishers.

[5] Shintani, N., Ellis, R., Suzuki, W. (2013). Effects of written feedback and revision on learners' accuracy in using two English grammatical structures. A Journal of Research in Language Studies. https://doi.org/10.1111/lang.12029

[6] Shrum, J. and Glisan, E. (2000). Teacher's handbook. $2^{\text {nd }}$ ed. Heinle \& Heinle Publishers.

[7] Soleimani, H. \& Heidarikia, H. (2017). The effect of translation as a noticing strategy on learning complex grammatical structures by EFL learners. Applied Linguistics Research Journal, 1(1), 1-12. https://doi: 10.14744/alri.2017.09797

[8] Sukasame, N., Kantho S., Narrot, P. (2014). A study of errors in learning English grammatical structures on tenses of Matthayomsuksa 4 students of the demonstration school, Khonkaen university. Procedia-Social and Behavioral Sciences, 116, 1934-1939.

https://doi.org/10.1016/j.sbspro.2014.01.498 